\title{
A Strategy for Teaching and Learning of Systematic DESIGN ENGINEERING
}

\author{
W. Ernst Eder \\ Royal Military College of Canada (retired) \\ eder-e@kos.net
}

\begin{abstract}
Systematic engineering design can use the tools, models and methods recommend by Hubka to help designers, especially in critical situations. These methods can be applied for novel designing, or for re-designing. In teaching, observations of students revealed difficulties in applying and formulating "internal and crossboundary functions" of technical systems (TS), and of "operations" in a transformation process (TrfP).

A strategy to overcome these difficulties is to introduce sufficient theory, then to provide a re-design problem, using an existing commercial device, (a) as a cut-away to show the inner workings, and (b) as a complete device that can be dis-assembled - accompanied by engineering drawings of each part, an assembly drawing and an exploded view. Students (1) studied the hardware and drawings, (2) identified elemental organs, and useful organ groups, and (3) wrote their interpretation of what each organ group is capable of doing - the TS-internal and/or cross-boundary functions, to be represented in a TS-function structure. An example is offered.
\end{abstract}

Keywords: Systematic engineering design, teaching/learningand since strategy, case examples

\section{INTRODUCTION}

Teaching and learning of engineering design has in the distant past been achieved by a form of apprenticeship the master designed according to his experience and knowing, the apprentice assisted (usually in detailing) and learned by observation. Starting around the 1950's, but more intensively since about the 1970's, more formal design methods have been developed, especially in two directions: (1) an overall design methodology attempting to cover the whole engineering design process, typified by Pahl and Beitz [22], and by Hubka [16,17,20,21,28], and (2) a concentration on one or other aspect of the engineering design process to develop detail methods, often with emphasis on creativity [2], see Eder [9].

Hubka started to develop his approach around 1965, since then continuously developed $[16,17]$ - based on a theory of technical systems, what all TS have in common, logically presented. The most important models for this paper are (a) a model of a general transformation system,

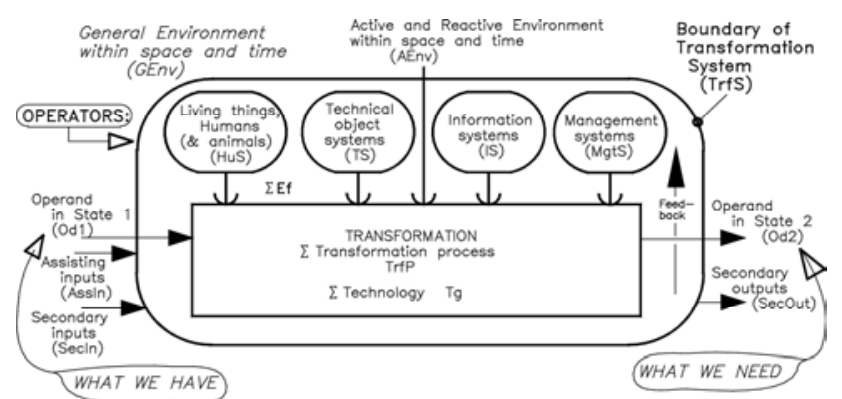

Fig. 1. GENERAL MODEL OF A TRANSFORMATION SYSTEM $[16,17,21]$.

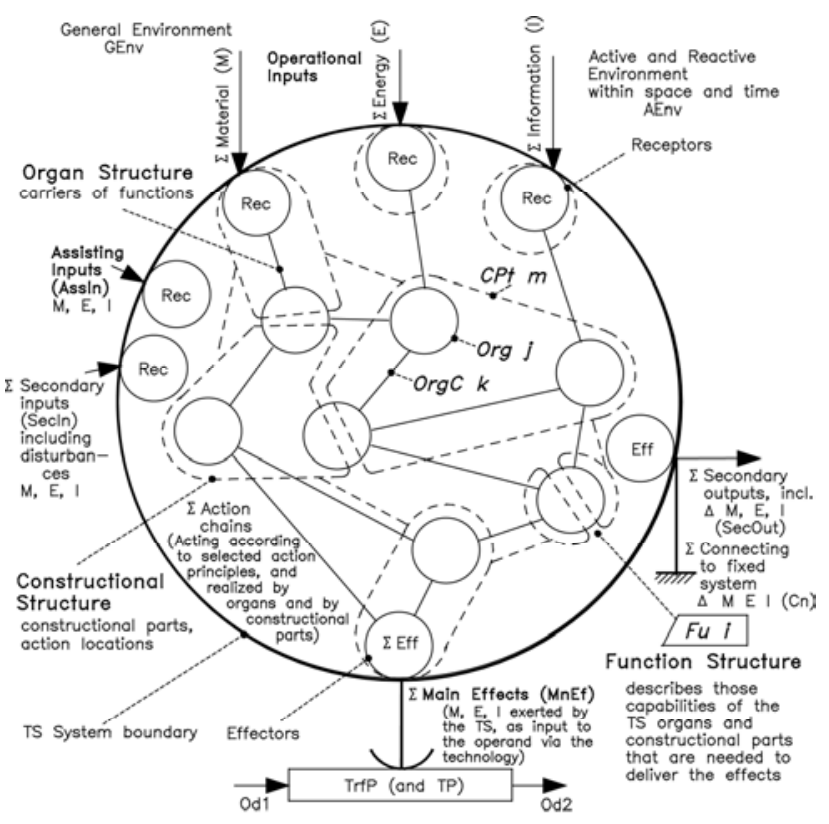

Each technical system exhibits several structures, consisting of different kinds of elements, e.g. functions ( $\mathrm{Fu} i \mathrm{i})$, organs (Org $\mathrm{j}$ ) and organ
connectors (OrgC k), constructional parts ( $\mathrm{CP} m$ ) and their relationships.

Fig. 2. STRUCTURES OF TECHNICAL SYSTEMS (TS MODELS) $[16,17,20,21]$. 
see figure 1, and (b) a model of useful structures recognizable internal to and across the boundary of a technical system (an operator in figure 1), see figure 2.

This theory of technical systems forms the basis for deriving a voluntary and consistent systematic engineering design method(ology) that also allows use of any of the hundreds of detail methods [9]. Justification for this approach was given in [3], and direct connections and comparisons to some other approaches were established, e.g. [4].

Systematic engineering design, as understood in this paper, uses the Hubka approach to recommend tools, models and methods to help engineering designers, especially in critical situations. The recommended method can be applied for novel designing, or for re-designing. Case examples (22 to date) show applications of the method, including complex problems and re-designing.

The first case study, systematic according to the state of the theory and method at that time, appeared in 1976 [18] - a machine vice. The second appeared in 1980 [20] - a welding positioner. The next three, also systematic, were published in 1981 in German - a riveting fixture, a milling jig, and a powder-coating machine - the first two were systematic, the third took an industrial-artistic design approach. The third set was published in 1983 - a $\mathrm{P}-\mathrm{V}-\mathrm{T}$-experiment, a hand winding machine for punched control tapes, and a tea brewing machine - again the first two were systematic, the third took an industrial-artistic design approach. An English edition was published in 1988 [19], and included the existing six case studies, plus two new items - a wave-powered bilge pump, and an oil drain valve - and again the bilge pump only loosely followed the systematic method. Three further case studies were published in 2008 [16] - the tea machine revised to current systematic procedures showing enhanced engineering information; re-design of a water valve [5]; and an electro-static smoke gas dust precipitator, with rapper for dust removal [6]. Three new case examples were published in 2010 [17] - a trapeze demonstration rig [7], re-design of an automotive oil pump [8], and a hospital emergency bed, with compensation devices for the support arrangement. Two other cases were prepared for the International Conference DESIGN 2012 [10,11], both from the Caravan Stage Barge [1] which has been in operation in Canadian and U.S.A. coastal waters, and now in the Mediterranean, since 1995. An RMC wind tunnel force balance accessory [12], and a Stage Barge gangway [13] were presented at CEEA2013. Stage barge life-boat davits [14] and a linear friction test research apparatus [15] will be presented in conferences during 2014.

Since 2010 [17], these case examples have been presented at the current latest stand of development of both the theory of technical systems, and the recommended systematic design process.

\section{A TEACHING/LEARNING STRATEGY}

In teaching these systematic engineering design methods at RMC, observations of students revealed that they found difficulties in applying and formulating concepts of "internal and cross-boundary functions" of technical systems (TS), and of "operations" in a transformation process (TrfP).

The best strategy to overcome these difficulties is to initially introduce sufficient theory by lecture or similar. This should especially cover the model of the transformation system, and the models of structures of technical systems - including detail consideration of the three main TS-internal and cross-boundary structures. As project work within the course, a simple re-design problem was introduced. Using an existing commercial device, (a) a cut-away was prepared to show the inner workings, and (b) a complete device that can be disassembled was supplied - accompanied by (reverseengineered) engineering drawings of each constructional part, and including an assembly drawing and an exploded view. Two case examples are available, a water valve $[5,16]$, and an automotive oil pump for engine lubrication $[8,17]$ - which were used in alternate years. Students were first invited (1) to study the hardware and drawings, and to check for any faults found in the drawings, (2) to identify elemental organs, and useful organ groups, and (3) to state in writing their own interpretation of what each organ group is capable of doing - these are the 'TSinternal and/or cross-boundary functions', which the students are asked to represent in a TS-function structure. Students then were given a new requirement to be considered, asked to set up a (revised) design specification, and to alter their TS-function structure accordingly. They then applied a morphological matrix to explore a revised solution, proposed some revised TSorgan structures, selected the one that in their opinion was best, and sketched a proposed layout.

Having overcome the student difficulty of formulating TrfP-operations and TS-internal and cross-boundary functions, this step-by-step strategy allowed setting one or more follow-up novel design problems, passing through all available TrfP and TS structures. Several of the existing case examples were also presented to the students and discussed in class.

\section{PARTIAL CASE EXAMPLE}

Parts of the re-design case example "automotive oil pump for engine lubrication" [8,17] are offered here to show the typical results expected from the first project. The usual sub-headings for a re-design case are followed, with comments where needed. Two identical oil pumps from internal combustion engines dating to the 1970's 
were found. The body (part A) and cover (part E) were cast iron parts, machined. One was cut open for demonstration, the other was loosely assembled for students to take apart and handle. New detail and assembly drawings were prepared, for instance figure 3 .

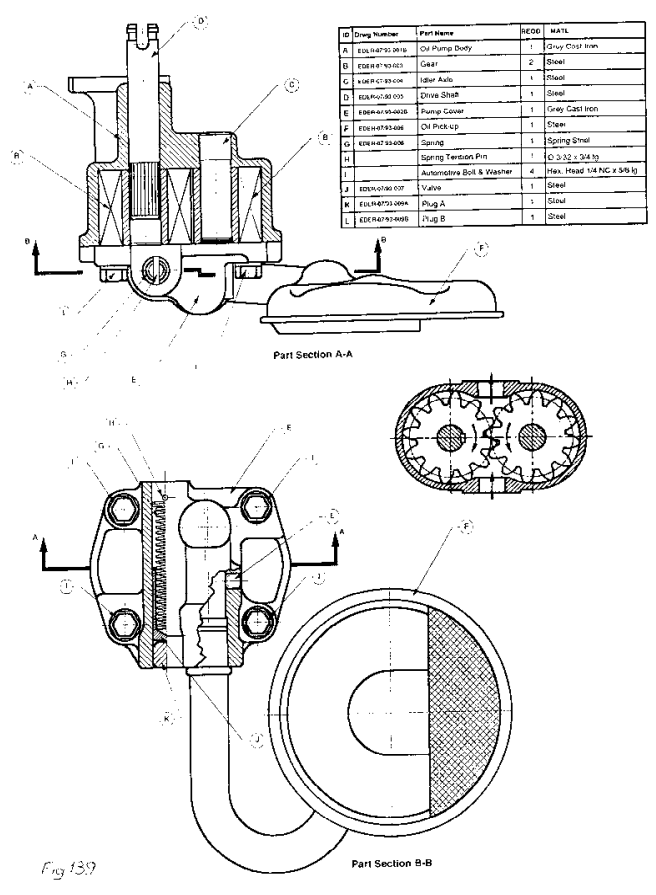

Fig. 3. OIL PUMP - ASSEMBLY SECTIONAL VIEWS AND PARTS LIST $[8,17]$.

(P1) Establish List of Requirements - investigate alter-natives

(P2) Establish a Plan for the Design Work - investigate alternatives

(P3a) Establish the Transformation Process - investigate alternatives (P3.1 - P3.1.4)

See figure 4.

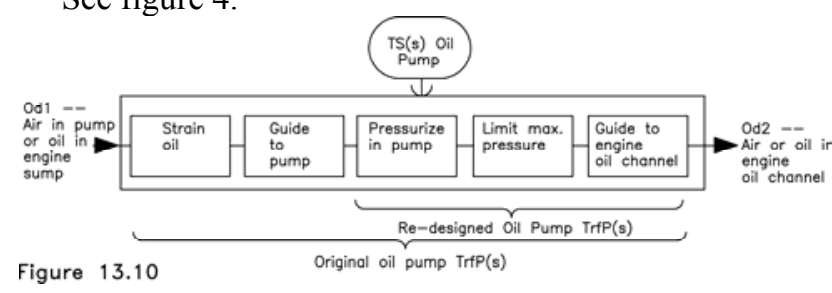

Fig. 4. OIL PUMP - TRANSFORMATION PROCESS $[8,17]$.

For this initial project, these three design steps were deferred until the new requirement was introduced. Normally, a re-design problem does not include a transformation process, it is only included here for clarity.

\section{(P1Rev) Amend Design Specification for New \\ Requirements:}

F Oil pump must be relocated outside of crank case.

$\mathrm{S}$ Strainer and suction pipe remain inside crankcase / oil pan.

F All parts must be easily accessible for repair.

PROCEDURAL NOTE: Step (P1Rev) has been placed here for the convenience of this paper, the students were informed about this step after they had completed their own TS-function structure for the given oil pump.

\section{(PRev5) Establish the Existing TS-Organ Structure by Reverse Engineering}

The revised design process starts from the existing assembly drawing, figure 3. This was first transformed into a 'skeleton' representation, ignoring all material thicknesses, see figure 5 - an organ structure. The revised boundary of the new TS(s) is also indicated.

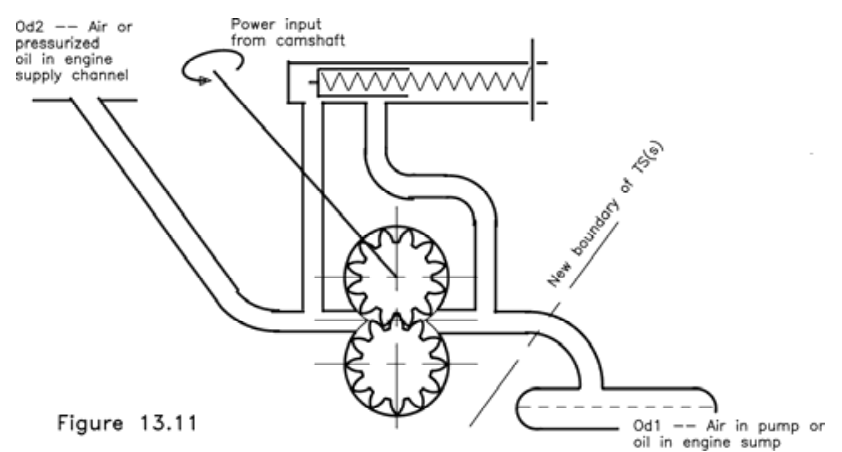

Fig. 5. OIL PUMP - SKELETON (ORGAN) DIAGRAM OF CONSTRUCTIONAL STRUCTURE $[8,17]$.

\section{(PRev4) Establish the Existing TS-Function Structure} by Reverse Engineering

By searching for significant contacts in both the assembly drawing or TS-constructional structure, and the TS-organ structure, figures 3 and 5, (a) between surfaces on adjoining constructional parts, (b) on constructional parts with the operand, and (c) with the active and reactive environment, elemental organs could be identified, together with their elemental functions, and organ groups.

PROCEDURAL NOTE: As a designer becomes more experienced, the typical organ structure of figure 5 is no longer as important, nor are the elemental organs - the organ groups can be 'read' directly from the TSconstructional structure.

Additional symbols needed: 
O - Oil operand (or air on start-up - Od1 and Od2 in figure 5)

$\mathrm{X}$ - Engine driving power supply

$\mathrm{Y}$ - Crankcase attachment flange

\section{Const. Description}

Organ

Parts Purpose (function verb)

Group

For the revised design specification, the following were no longer needed, they remain within the crankcase as constituent parts of the engine (Note that the above headings apply to all organs and/or organ groups):

O1-F

Oil in sump to pick_up collect and strain oil

F-E

Oil pick-up to cover form guide for oil into cover

By inspection, the following were recognized as organs evoked by manufacturing requirements, they do not need to be considered for a revised TS-function structure, some of them may need to be re-considered in the new TS-constructional structure:

B1-D

Gear bore to drive shaft transmit driving torque, manufacturing auxiliary, press fit

C-A

Idler axis to body manufacturing auxiliary, press fit

E-L

Plug for transfer port manufacturing auxiliary, through drilling

E-K

Plug for valve guide manufacturing auxiliary, through boring A-E

Cover to body seal against outward leakage

\section{A-E-I}

Cover to body fastening hold parts together

Connections to the fixed system 'engine' were found as:

A-Y

Body to crankcase attachment hold parts together

A-Y-O2

Body to crankcase oil channel allow transfer of pressurized air/oil

O1-Y-A

Crankcase oil channel to body allow transfer of sucked oil

D-X

Drive shaft slotted end accept torque and rotation
The organ grouping OG1 reflects the connection requirements for the revised oil pump. Elemental organs were selected to form the following two typical organ groups, and to formulate the appropriate functions mainly as an educational demonstration exercise to show that elemental organs combine into useful groups:

A-B

Body flat bore face to gear face seal against back leakage

A-B

Body cylinder to gear tooth tip seal against back leakage

E-B

Cover flat face to gear face seal against back leakage

B1-B2

Gear tooth mesh seal against back leakage

A-B-E

Gear tooth gap, flanks and root package oil for transport

The appropriate TS-functions for this organ $\overline{\text { group }}$ are:

Fu1 "isolate a series of volumes that can be rotated from an input space to an output space", and

Fu2 "adequately reduce back-leakage of oil".

J-E

Valve to cover guide seal against outward leakage

J-E

Valve to cover guide allow axial movement

O2-J

Oil to valve head transform oil pressure to force

J-E

Valve to cover transfer port open/close oil by-pass

J-G

Valve to spring transfer axial force

G-H

Spring to pin react spring force to cover

H-E

Pin to cover retain valve and spring

The TS-functions for this organ group are:

Fu3 "sense operand-space pressure"

$\mathrm{Fu} 4$ "move sensor proportionally to pressure"

Fu5 "at pressure limit, open by-pass port to allow operand into entry space"

Fu6 "seal against outward leakage"

The other organ groups were identified by inspection, without specifying the elemental organs: 
X-D

Drive in engine to shaft end accept torque and rotation

D-B1

Shaft end to driving gear transmit torque and rotation

D-A

Driving gear shaft to body locate shaft in body

B1-B2

Driving gear to idler gear transmit tangential force and rotation

B2-C-A

locate idler in body

E-A

Cover to body transfer oil to gear mesh entry

TS-functions for these organ groups were formulated, the TS-function structure for the revised oil pump is shown in figure 6.

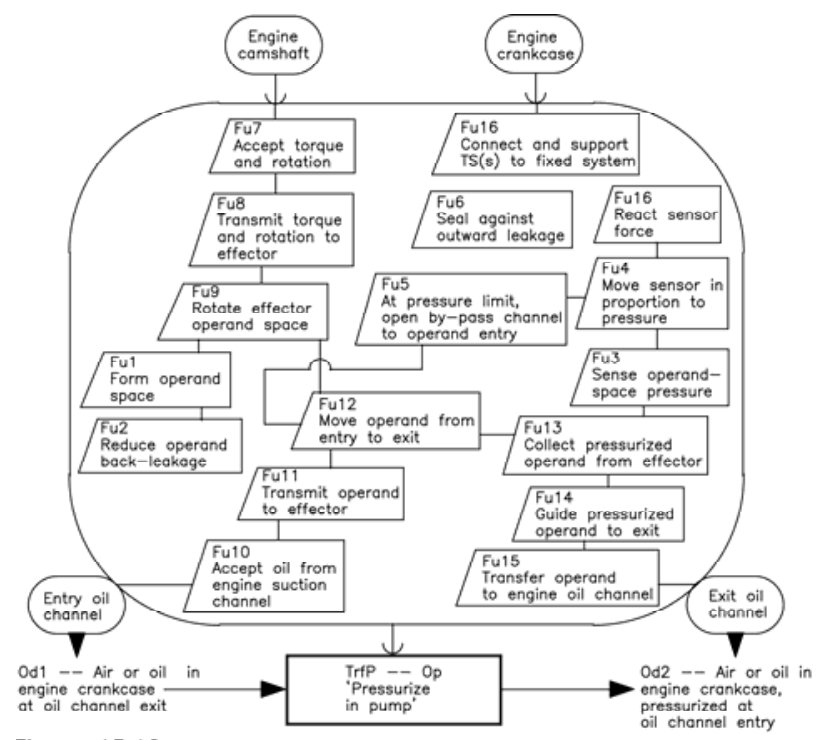

Figure 13.12

Fig. 6. OIL PUMP - FUNCTION STRUCTURE $[8,17]$

\section{(P4) Establish the TS(s) - Organ Structure - investigate alternatives}

Only three TS-functions need to be explored for alternatives, Fu12, and the groups of $\mathrm{Fu} 3 / \mathrm{Fu} 4 / \mathrm{Fu} 5$ and Fu11/Fu13, see figure 7. A formal morphological matrix is probably not needed, it would contain only three rows. Systematic sub-division of the appropriate concepts helped to make the survey as complete as practicable. The resulting organ structure is ready for a dimensional layout and detailing, see figure 8 .
At the end of this project, students were given a copy of reference [8], and allowed to handle a loosely fitted sample of an aluminum-bodied Wankel-style [23] external oil pump as fitted by a notable manufacturer.

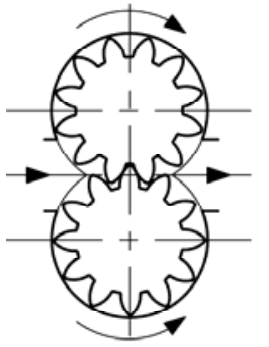

(A) Gear Pump

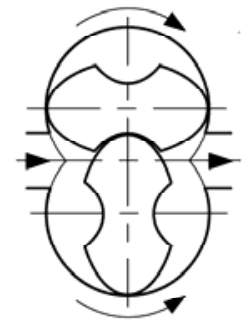

(B) Undercut Gear Pump (Roots)

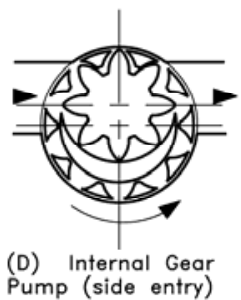

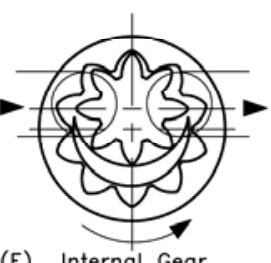

(E) Internal Gear
Pump (end entry)

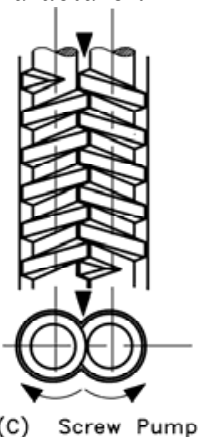

(C) Screw Pump

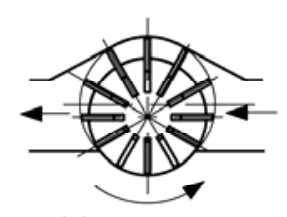

(G) Vane Pump

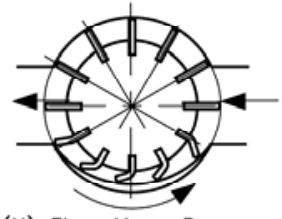

(H) Flex. Vane Pump

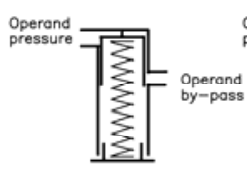

(J) Cyl. Piston

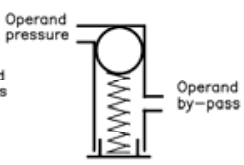

(K) Sphere closure

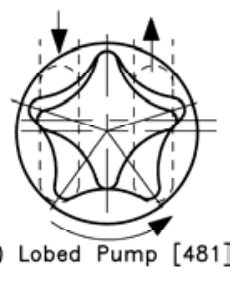

Figure 13.13

Fig. 7. OIL PUMP - PRINCIPLES OF OPERATIONMORPHOLOGY FOR FU12 AND FU3/FU4/FU5 [8, 17,23]

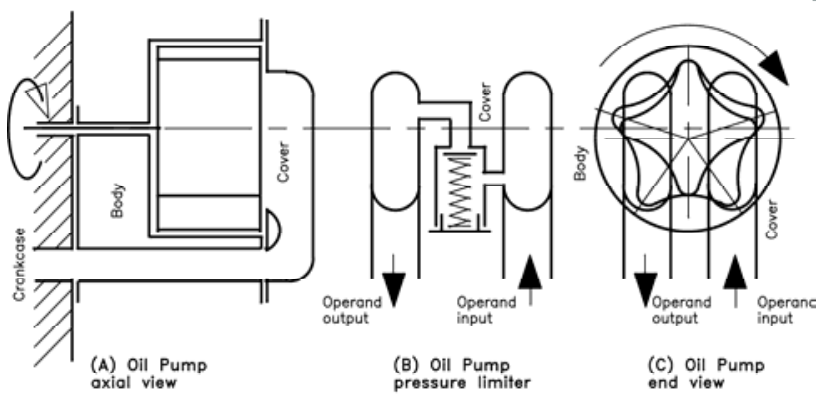

Figure 13.14

Fig. 8. OIL PUMP - PROPOSED ORGAN STRUCTURE $[8,17]$

\section{CLOSURE}

This approach was found to be successful. 


\section{References}

[1] Caravan Stage Barge, http://www.caravanstage.org

[2] Eder, W.E. (ed.) (1996) WDK 24 - EDC - Engineering Design and Creativity - Proc. of the Workshop EDC, Pilsen, Czech Republic, November 1995, Zürich: Heurista

[3] Eder, W.E. (2009) 'Why Systematic Design Engineering?' in Proc. 6th Symposium on International Design and Design Education, August 30 - September 2, 2009, San Diego, CA, USA, New York: ASME, paper number DETC2009-86067

[4] Eder, W.E. (2010) 'Requirements to Properties - Iterative Problem Solving', in Proc. Canadian Engineering Education Association 2010 Inaugural Conference, 7-9 June 2010, Queen's University, Kingston, ON

[5] Eder, W.E. (2006) 'Case Study in Design Engineering' in Proc. CDEN 06 Toronto, 24-26 July 2006, on CD-ROM p. 332-338

[6] Eder, W.E. (2009) 'Case Study in Systematic Design Engineering - Smoke Gas Dust Precipitation', paper ASME DETC2009-86069 in Proceedings of the $6^{\text {th }}$ Symposium on International Design and Design Education, DEC 6, August 30 - September 2, 2009, San Diego, CA, USA

[7] Eder, W.E. (2010) 'Case Study in Systematic Design Engineering - Trapeze Demonstration Rig', paper ASME DETC2010-28065 in Proc. 7th Symposium on International Design and Design Education, DEC 7, 1518 August 2010, Montreal, Quebec, Canada

[8] Eder, W.E. (2010) 'Case Study in Systematic Design Engineering - Automotive Oil Pump Redesign', paper ASME DETC2010-28073 in Proc. $7^{\text {th }}$ Symposium on International Design and Design Education, DEC 7, 1518 August 2010, Montreal, Quebec, Canada

[9] Eder, W.E. (2012) 'Comparisons of Several Design Theories and Methods with the Legacy of Vladimir Hubka', private publication ( 74 pages) available from eder e $a$,kos.net, and on the web-site of The Design Society, www.designsociety.org, select 'resources', 'publications', 'public reports'

[10] Eder, W.E. (2012) 'Case Example in Systematic Design Engineering - Leeboard Mounting', in Proc. International Design Conference - DESIGN 2012, Dubrovnik - Croatia, May 21-24, 2012

[11] Eder, W.E. (2012) 'Case Example in Systematic Design Engineering - Propeller Shaft Bearing Arrangement', in Proc. International Design Conference - DESIGN 2012, Dubrovnik - Croatia, May 21-24, 2012

[12] Eder, W.E. (2012) 'Case Study in Systematic Design Engineering - Wind Tunnel Balance Model Support', paper number 9 in Proc. Canadian Engineering Education Association CEEA 2012 Conference, 17-20 June 2012, University of Manitoba, Winnipeg, MB

[13] Eder, W.E. (2013) 'Systematic Conceptualizing - a Case Example - Stage Barge Gangway', paper number 6 in Proc. Canadian Engineering Education Association CEEA 2013 Conference, 17-20 June 2013, Ecole Polytechnique Montreal

[14] Eder, W.E. (2014) 'Case Study in Systematic Design Engineering - Life-boat Davits', for Proc. Tools and Methods in Competitive Engineering - TMCE 2014 Symposium - 19-23 May 2014, Budapest, Hungary (in press)

[15] Eder, W.E. (2014) 'Case Example of Systematic Design Engineering - Linear Friction Test Equipment', for Proc $3^{\text {rd }}$ International Conference on Design Engineering and Science - ICDES 2014, Japan Society for Design Engineering, 31 Aug - 3 Sept 2014, Pilsen, Czech Republic (in press)

[16] Eder, W.E. and Hosnedl, S (2008) Design Engineering: A Manual for Enhanced Creativity, Boca Raton: CRC Press

[17] Eder, W.E. and Hosnedl, S. (2010) Introduction to Design Engineering - Systematic Creativity and Management, Leiden (The Netherlands): CRC/Balkema

[18] Hubka, V. (1976) Theorie der Konstruktionsprozesse (Theory of Design Processes), Berlin: Springer-Verlag

[19] Hubka, V., Andreasen, M.M. and Eder, W.E. (1988) Practical Studies in Systematic Design, London: Butterworths, (English edition of WDK 4 - Fallbeispiele, Zürich: Heurista, 1981 and 1983)

[20] Hubka, V. and W.E. Eder (1992) Engineering Design, Zürich: Heurista, (2nd edition of Hubka, V., Principles of Engineering Design, London: Butterworth Scientific, 1982, translated by W.E. Eder from Hubka, V., WDK 1 Allgemeines Vorgehensmodell des Konstruierens (General Procedural Model of Designing), Zürich, Heurista, 1980

[21] Hubka, V. \& Eder, W.E. (1996) Design Science: Introduction to the Needs, Scope and Organization of Engineering Design Knowledge, London: Springer-Verlag, http://deseng.ryerson.ca/DesignScience/

[22] Pahl, G., Beitz, W., Feldhusen, J. and Grote, H-K., Engineering Design ( 3 edn.), London: Springer-Verlag, 2007 (1 edn. 1984) (Edited and translated by K. Wallace and L. Blessing from 2003-5th edn. of Pahl, G. et al Konstruktionslehre, Methoden und Anwendungen, (7 edn.) Berlin/Heidelberg: Springer-V., 2007 (1 edn. 1977)

[23] Wankel, F., Rotary Piston Machines, London: Iliffe, 1965 ([481] in figure 7 